\title{
Title: Older Adults Have Diminished Awareness of Errors in the Laboratory and Daily Life.
}

\author{
Authors: Siobhán Harty ${ }^{1}$, Redmond G O’Connell ${ }^{1}$, Robert Hester ${ }^{2}$ \& Ian H \\ Robertson $^{1}$
}

\author{
Affiliations: \\ ${ }^{1}$ Trinity College Institute of Neuroscience and School of Psychology, Trinity College \\ Dublin, Dublin 2, Ireland. \\ ${ }^{2}$ University of Melbourne, Department of Psychological Sciences, Melbourne, \\ Victoria, Australia.
}

Correspondence concerning this article should be addressed to Siobhán Harty, Trinity College Institute of Neuroscience, Lloyd Building, Trinity College Dublin, Dublin 2, Ireland.

E-mail: sharty@tcd.ie

Acknowledgements: We would like to thank Gina Mirow and Hannah Wolfe for valuable assistance with data collection. We would also like to thank Dr. Sabina Brennan for developing the Choice Reaction Time task. 


\section{ABSTRACT:}

Poor recognition of the degree or scope of one's own cognitive deficits is a common feature of many neurological conditions, including diseases of aging, but little is known about the impact the natural aging process has on this aspect of selfawareness. Here, a group of 45 healthy older adults and a comparison group of 45 young adults $(\mathrm{N}=45)$ completed a multi-domain assessment of self-awareness. Awareness of daily functioning was evaluated based on discrepancies between selfand informant- ratings on questionnaire measures of attentional control, memory functioning and socio-emotional functioning. Online error awareness was also assessed using a variant of the Go/No-Go Error Awareness Task in which participants are required to signal commission errors via a separate manual response. While younger participants tended to underestimate their attentional control and memory functioning relative to informant reports, older adults significantly overestimated their abilities. The older adults also exhibited substantially poorer online error awareness compared to young adults despite the fact that the two groups were matched for overall accuracy. Levels of online error awareness were significantly correlated with discrepancy scores for daily attentional and memory functioning, and with performance of a sustained attention task. These novel findings suggest that an important aspect of the neuropsychology of healthy aging has hitherto been overlooked.

Keywords: Cognitive Aging, Self-Awareness, Error Awareness, Prefrontal Cortex, Sustained Attention.

Abstract: 209 


\section{MAIN TEXT:}

We are all prone to occasional lapses or errors as we engage in our daily activities. Although the errors themselves typically have unfavorable consequences, they can also play a critical adaptive role by signaling to us that current performance levels are not sufficient to attain our goals, and by allowing us to establish accurate impressions of our own abilities. The capacity to monitor performance errors is particularly important from a clinical perspective, as compromised self-awareness (SA) of a deficit will necessarily impede the patient in making efforts to recover from it, or implement compensatory strategies. Indeed, numerous studies have documented associations between poor SA of deficits and a range of negative outcomes, including poor motivation for treatment (Fleming, Strong \& Ashton, 1996; Malec \& Moessner, 2001), increased care-giver burden (Seltzer, Vasterling, Yoder, \& Thompson, 1997) and poor general prognosis (David, 1992; McEvoy, Apperson, Appelbaum, \& Ortlip, 1989). The natural aging process is known to have a deleterious effect on a wide range of cognitive functions (Grady, 2012; Heddin \& Gabrieli, 2004; McAvinue, Habekost, Johnson, et al., 2012; Salthouse, 1996), rendering older adults more prone to erroneous behavior (e.g. Burke \& Shafto, 2004; Gold, Powell, Xuan, Jicha \& Smith, 2010; Young \& Bunce, 2011), yet very little research has examined SA of deficits in healthy older adults.

Functional imaging work has suggested that the neural substrates of SA reside across a distributed network of brain regions (Pia, Neppi-Modona, Ricci, et al. 2004; Prigatano \& Schacter, 1991; Rosen, Alcantar, Rothlind et al., 2010), but the robust association between compromised prefrontal cortex (PFC) function and SA deficits across several different clinical populations, including traumatic brain injury 
(O’Keeffe, Dockree, Moloney, Carton, \& Robertson, 2007), schizophrenia (David, Bedford, Wiffen \& Gilleen, 2012), substance abuse (Hester, Nestor, \& Garavan, 2009), Alzheimer's Disease (Starkstein, Vázquez, Migliorelli, et al., 1995), attentiondeficit/hyperactivity disorder (O'Connell, Bellgrove, Dockree, et al., 2009) and focal frontal lesions (Hoerold, Pender \& Robertson, 2013), indicates that the PFC is a particularly important component of the SA network. Although the neuropsychological underpinnings of SA have yet to be fully established (Prigatano, 2005) reduced SA has frequently been linked to memory impairment (e.g. Agnew \& Morris, 1998; Starkstein et al., 1995; Noe et al., 2005), and findings within our own laboratory have demonstrated a close relationship between SA and sustained attention (for an overview, see Robertson (2010)). Given that the PFC is particularly vulnerable to the effects of aging (e.g. Heddin \& Gabrieli, 2004), and that memory and attentional capacities are known to decline with increasing age (see Balota, Dolan, \& Duchek, 2000 for a review), there is basis for hypothesizing that the capacity for SA may be reduced in older adults.

Findings from the field of electrophysiology have provided some valuable information on how the aging brain responds to errors. Of particular importance has been the study of two event-related brain potentials (ERP) that occur when people make errors on laboratory tasks: the error negativity (Ne; Falkenstein, Hohnsbein, Hoormann, \& Blanke, 1990) and the error positivity (Pe; Falkenstein, Hohnsbein, Hoormann, \& Blanke, 1991). The precise functions of the Ne and Pe are still under debate, but it is generally assumed that the Ne reflects an early, rapid, and possibly preconscious, detection mechanism that is sensitive to response conflict (van Veen \& Carter, 2002) or changes in reward probability (Holroyd \& Coles, 2002). The Pe, on the other hand, has been linked to conscious error awareness, owing to the consistent 


\section{SELF-AWARENESS AND AGING}

observation that it is only present on trials where participants are aware of their errors (Endrass, Franke, \& Kathmann, 2005; Murphy, Robertson, Allen, Hester \& O’Connell, 2012; Niewenhuis, Ridderinkhof, Blom, Band, \& Kok, 2001; O’Connell, Dockree, Bellgrove et al., 2007). A number of studies have found that the amplitudes of both the Ne (Band \& Kok, 2000; Falkenstein, Hoormann, Christ, \& Hohnsbein, 2000; Mathalon et al., 2003; Mathewson, Dywan \& Segalowitz, 2005) and the Pe

(Band \& Kok, 2000; Falkenstein, Hoormann, Christ, \& Hohnsbein, 2000; Leuthold \& Sommer, 1999; Mathewson et al., 2005) are reduced in older adults relative to young controls. However, participants did not overtly signal their errors in these studies and therefore it cannot be determined to what extent attenuation of the trial-averaged $\mathrm{Pe}$ results from reduced error awareness or from differences in the processing of consciously detected errors.

Outside of the field of electrophysiology, a small number of studies have suggested that older adults demonstrate a diminished ability to monitor and appraise performance (Bruce, Coyne, \& Botwinick, 1982; Graham, Kunik, Doody, \& Snow, 2005; Rabbitt, 1990; Suchy, Kraybill, Frnachow, et al., 2011), but others have provided some evidence to the contrary (Clare, Whitaker, \& Nelis, 2010; Lovelace \& Marsh, 1985; Rabbitt, 2002). Overall, the research on SA in healthy aging is not conclusive, and of particular import, these studies have not measured SA across a range of cognitive and behavioral domains, which is important given the potential domain specificity of SA deficits (e.g. Hart et al., 2005; Hart, Sherer, Whyte et al., 2004; Prigatano \& Altman, 1990). In the present study we aimed to address this gap in the literature by employing the first multi-domain assessment of SA in healthy older adults. 
The most common method for measuring SA in patient populations is to examine the discrepancy between self-reports and informant-reports on questionnaire measures of daily functioning, with the premise that a discrepancy in the direction of the informant reporting more difficulties indicates impaired SA (Fleming, Strong \& Ashton, 1996; Hart et al., 2004). We examined SA in terms of attentional control, memory functioning and socio-emotional functioning, respectively, using this questionnaire discrepancy score method. We also administered a computerized measure of SA that required participants to overtly signal their errors (i.e. demonstrate online error awareness) during a neuropsychological task. A number of authors have argued that online error awareness enables recognition of difficulties as they occur, and may therefore contribute to broader aspects of SA in daily life (Jenkinson, Edelstyn, Drakeford, \& Ellis, 2009; Larson \& Perlstein, 2009; Ownsworth \& Fleming, 2005; Robertson, 2010). However, such a relationship has yet to be established empirically, and was accordingly identified as an important question for the current study. A battery of neuropsychological tests were also administered to obtain cognitive profiles of the participants and to examine the relationship between SA and other cognitive domains.

Given that SA is linked to PFC function, as well as cognitive capacities such as attentional control and memory, all of which are known to deteriorate with increasing age, we hypothesised that older adults would have diminished SA relative to young adults. We also predicted that online error awareness would be associated with questionnaire measures of SA, and that SA would correlate positively with sustained attention and memory capacities. 


\section{METHOD}

\section{Participants}

Fifty-one older adults and 47 young adults took part in the study. Four older adults were excluded because their Mini-Mental State Examination (MMSE, (Folstein, Folstein \& Hugh, 1975) score indicated possible cognitive impairment $(<24)$. Two older and two younger adults were also excluded due to poor accuracy on the Error Awareness Task $(<30 \%$ correctly withheld no-go trials). As a result, the final sample consisted of 45 younger adults (31 female) with a mean age of 22.7 years (SD 4.9, range 18-34) and 45 older adults (29 female) with a mean age of 76.2 years (SD 7.1, range 66-90). Exclusion criteria were visual impairment, history of psychiatric illness, neurological insult, drug or alcohol abuse, and/or reporting current use of antipsychotic or antidepressant medications. The most common illnesses for which older adults were taking medication for were hypertension $(n=10)$, osteoporosis $(n=$ 5), arthritis $(n=5)$, and hypothyroidism $(n=4)$. All participants were asked to refrain from consuming caffeine on the day of testing. Procedures were approved by the ethical review board of the School of Psychology, Trinity College Dublin in accordance with the Declaration of Helsinki, and all participants provided informed consent.

\section{Background Measures}

A number of background neuropsychological tests and measures were administered to all participants. These included: The Mini-Mental State Examination (MMSE), the National Adult Reading Test (NART; Nelson, 1982; Nelson and Willison, 1991), Logical Memory 1 (immediate recall) subtest of the Wechsler 
Memory Scale (WMS-III; Wechsler, 1997), a test of verbal fluency (animal naming), the Sustained Attention to Response Task (SART; Robertson et al., 1997), and a twochoice reaction time task (CRT). Participants also completed the Hospital Anxiety and Depression Scale (HADS; Zigmond and Snaith, 1983) to assess symptoms of anxiety and depression.

For both the SART and the CRT, stimuli were presented on a Dell Latitude Laptop using E-prime 2.0 software (Psychology Software Tools, Inc, PA, USA). For the SART, the numbers 1 to 9 appeared in a fixed sequence and participants were required to make a left button click for every number except for the number three. Participants completed two blocks of the task, each of which included 25 No-go targets (the number 3) and 200 Go trials (all other numbers). The CRT was included as a measure of speed of processing. Each trial of the CRT started with the participant holding down a white central button on a RB-530 response box (Cedrus, San Pedro, CA, USA) to trigger target onset. Participants were then required to make a speeded press of a 'green' button if the target 'YES' appeared on screen or a 'red' button if the target 'NO' appeared. They were instructed to return to the white button after target offset to trigger the next target. To guard against pre-emptive responding target offset could not be achieved if the white button was released before the target appeared. The task comprised 50 'NO' trials and 50 'YES' trials presented in random order. The interval between depression of the white trigger button and the target onset varied between $800 \mathrm{~ms}$ and $1100 \mathrm{~ms}$. The task was self-paced, but participants were instructed to respond quickly and accurately. Speed of processing was measured in milliseconds and was split into a 'cognitive response' measured as time from target onset to trigger offset (release of white key) and 'motor response' measured as time from trigger offset to response selection (depression of green key or red key). 


\section{Awareness Measures}

The Error Awareness Task (EAT; Hester, Foxe, Molholm, Shpaner, \& Garavan, 2005) was used as a measure of online error awareness, and questionnaire measures of daily functioning included the Cognitive Failures Questionnaire (CFQ; Broadbent, Cooper, Fitzgerald, \& Parkes, 1982), the Socio-Emotional Questionnaire (SEQ; Bramham, Morris, Hornak, Bullock, \& Polkey, 2009) and the Memory Awareness Rating Scale, Memory Functioning Scale (MFS; Clare et al., 2002).

\section{The Error Awareness Task}

The EAT is a Go/No-go response inhibition task in which participants are presented with a serial stream of single color words, with congruency between the semantic meaning of the word and its font color manipulated across trials. Participants were trained to respond with a single speeded left mouse button press in situations where the meaning of the word and the font color in which it was presented were congruent (Go trial) and to withhold this response when either of two different scenarios arose: (1) when the word presented on the current trial was the same as that presented on the preceding trial (Repeat No-go trial), and (2) when the meaning of the word and its font color did not match (Incongruent No-go trial). In the event of a commission error (failure to withhold to either of these No-go trials) participants were trained to signal their "awareness" by making a right mouse button press on the subsequent trial. In these instances they were not required to make their standard Gotrial response. The next standard Go-trial after an error was thus rendered irrelevant which guarded against the possibility that some errors may fail to reach awareness because ongoing processing has been interrupted by the onset of another stimulus (Rabbitt, 2002). 
In addition, due to concerns that group differences in online error awareness on this task might arise purely from group differences in the number of errors made, we integrated a feature that adaptively modified the difficulty of the task. This entailed checking the participants' accuracy over consecutive periods of 40 trials and adapting the stimulus duration accordingly. The first 40 stimuli of the task were always presented for $750 \mathrm{~ms}$ and were succeeded by an inter-stimulus interval (ISI) of $750 \mathrm{~ms}$. The stimulus duration subsequently remained at $750 \mathrm{~ms}$ as long as accuracy on the previous 40 trials was between $50 \%$ and $60 \%$. However, if accuracy exceeded $60 \%$ the stimulus duration and ISI were set to $500 \mathrm{~ms}$ and $1000 \mathrm{~ms}$ respectively for the subsequent 40 trials. If accuracy fell below 50\%, the stimulus duration and ISI were set to $1000 \mathrm{~ms}$ and $500 \mathrm{~ms}$ respectively. This evaluation and task adjustment occurred every 40 trials thereafter. All participants performed four blocks of the task, consisting of 225 word presentations, 200 of which were Go trials and 25 of which were No-go trials (12 Repeat No-gos and 13 Incongruent No-gos, or vice versa). The duration of each block was approximately $5.6 \mathrm{~min}$. It was ensured that all participants were well-practiced and fully understood the requirements of the task before they began their first block.

\section{The Cognitive Failures Questionnaire}

The CFQ is a 25-item scale that includes statements relating to levels of attentional control in daily life. It has been employed in a broad range of clinical and non-clinical populations and has high construct validity (e.g. Larson et al., 1997; Wallace, Kass, \& Stanny, 2002; Wallace \& Vodanovich, 2003). The specificity of the CFQ as a measure of attentional control, rather than global cognitive function, is borne out by research indicating that the scale is not correlated with general 


\section{SELF-AWARENESS AND AGING}

intelligence but is robustly correlated with objective indices of attention (Manly, Robertson, Galloway \& Hawkins, 1999; Robertson et al., 1997; Tipper \& Baylis, 1987). Higher CFQ scores indicate poorer perceived attentional control.

\section{The Memory Functioning Scale}

The MFS is comprised of 13-items that ask about individuals ability to perform memory tasks in a range of everyday situations. The scale has been validated in healthy aging and early stage Alzheimer Disease (Clare, Whitaker \& Nelis., 2010). Higher MFS scores indicates better perceived memory functioning.

\section{The Socio-Emotional Questionnaire}

The SEQ is a 30 -item scale that includes statements relating to the recognition of basic emotions, empathy with the expression of these emotions, relationship skills and public behavior. The SEQ has demonstrated reliability and validity in brain injury patients (Bramham et al, 2009) and healthy adolescents (Wall, Williams, Morris \& Bramham, 2011). Higher scores indicate poorer perceived socioemotional functioning.

Each of the questionnaire measures of awareness was rated for identical items by participants and an informant. All informants were aged between 20 and 64 years (Mean 48.16, SD 10.59), had known the participant for 2 years or more, and had spent 6 hours or more with the participant in the 2 months preceding completion of the questionnaires. Discrepancy scores were calculated correcting for differences in direction of scoring. The difference between self-ratings and informant ratings were divided by the mean of the two sets of ratings to prevent scaling effects from 
distorting the measurement (Clare, Whitaker, \& Nelis, 2010; Clare, Whitaker, Nelis, et al., 2011). Corrected discrepancy scores close to zero indicate good agreement between the participant and the informant. For all three measures, positive scores indicated that the informant reported more difficulties than the participant, and vice versa.

\section{Statistical Analysis}

All of the neuropsychological tests, as well as performance indices on the EAT were analyzed using one-way ANOVAs. Due to the fact that response times (RT) to Go-trials following a No-go trial were likely to be disrupted by errorsignaling responses, trials up to $n+1$ relative to the error-signaling response were excluded from the Go-trial RT analysis. For the questionnaire measures of SA, univariate ANCOVAs were performed on each of the corrected discrepancy scores with Age Group (two-level) as the between subjects factor. Significant group differences were found for speed of cognitive response, speed of motor response, anxiety and depression, therefore all of these variables were entered as covariates. Significant main effects $(p<.05)$ were followed up with Bonferroni adjusted paired and independent samples t-tests to determine the origin of the effect of Age Group. All reported effects were significant regardless of whether the covariates were included or not. To examine, the interrelationships between the different domains of SA, and the extent to which the domains of SA related to the cognitive capacities for sustained attention, memory and verbal fluency, we conducted one-tailed Bonferroni adjusted partial correlations controlling for speed of cognitive response, speed of motor response, anxiety and depression. Again, all reported effects were significant regardless of whether the covariates were included or not. 


\section{RESULTS}

The demographic and neuropsychological data for both groups are summarized in Table 1 . The groups were successfully matched for $\operatorname{sex}\left(\chi^{2}(1)=.20, p\right.$ $=.655)$ years of education $(F(1,88)=.076, p=.783)$ and estimated IQ $(F(1,88)=$ $3.63, \mathrm{p}=.060)$. Young adults reported higher levels of anxiety $(F(1,88)=20.19, p<$ $.001)$ and depression $(F(1,88)=11.40, p<.01)$ than older adults. Significant effects of Age Group were observed for all of the background neuropsychological tests. Older adults had significantly lower MMSE $(F(1,88)=23.36, p<.001)$, memory $(F(1,88)=25.69, p<.001)$, sustained attention $(F(1,88)=10.60, p<.01)$ and verbal fluency $(F(1,88)=38.43, p<.001)$ scores than young adults. Older adults also had a slower cognitive response $(F(1,88)=46.75, p<.001)$ and slower motor response $(F(1,88)=75.80, p<.001)$, compared to young adults. Thus, although all participants were within the normal range for healthy older adults, older adults showed the expected age-related decline in cognitive function.

\section{Table 1 about here}

\section{Do older adults show a deficit in self-awareness?}

To test our hypothesis that older adults would show a deficit in SA we examined group differences in the Error Awareness Task, and discrepancy scores on the CFQ, MFS and SEQ.

\section{Error Awareness Task}

Performance indices for the EAT are summarized in Table 2. In order to maximize the number of trials in our analyses, and because there was no Age Group $\times$ Target Type interaction for error awareness $(p=.818)$, we did not distinguish between 
Repeat No-go's and Incongruent No-go's in any analyses. There were no significant group differences in accuracy $(p=.659)$, as would have been expected given that task difficulty varied as a function of accuracy, but older adults required significantly longer stimulus durations than young adults $(F(1,88)=6.14, p<.05)$ to attain such levels of accuracy. Older adults also had significantly slower reaction times for go trials $(F(1,88)=109.03, p<.001)$.

Despite comparable accuracy levels, older adults were aware of a substantially smaller percentage of their errors $(57.17 \%)$ compared to younger adults $(81.83 \%)$, even when error signalling responses were accepted up to three trials following an error, and when stimulus duration, speed of cognitive response, speed of motor response, anxiety and depression were controlled for $(F(1,81)=14.41, p<.001)$.

\section{Table 2 about here}

Figure 1 about here

\section{Questionnaire Measures of Awareness}

The mean ratings for all participants and informants, as well as the associated discrepancy scores on the CFQ, MFS and SEQ are presented in Table 3. The discrepancy scores for the CFQ, MFS and SEQ hereafter will be referred to as CFQD, MFS-D and SEQ-D, respectively.

\section{The Cognitive Failures Questionnaire}

There was a main effect of Group on CFQ-D $(F(1,81)=9.28, p<.01)$, indicating an age-related change in discrepancy scores (see Figure 2). Planned comparisons indicated that older adults reported significantly fewer difficulties with attentional control relative to their informants $(p<.025)$, whereas young adults did 


\section{SELF-AWARENESS AND AGING}

not differ from their informants $(p>.025)$. As seen in Table 3, these group differences were driven by changes in informant reports $(p<.025)$ as opposed to selfreports $(p>.025)$.

\section{The Memory Functioning Scale}

There was also a main effect of Group on MFS-D $(F(1,81)=18.96, \mathrm{p}<.001)$. Planned comparisons indicated that that older adults reported significantly fewer difficulties with memory functioning relative to informants $(p<.025)$. Young adults, on the other hand, reported significantly more difficulties with memory functioning than informants $(p<.025)$. Again, as seen in Table 3, these group differences were driven by changes in informant reports $(p<.025)$ as opposed to self-reports $(p>$ $.025)$.

\section{The Socio-Emotional Questionnaire}

In contrast to the CFQ and MFS findings, there was no main effect of Age Group on SEQ-D $(p>.05)$. As seen in Table 3 there was good agreement between both younger and older adults self-reports and informant reports, suggesting that age does not have a significant effect on awareness of social functioning.

In order to verify the accuracy of the informants' reports we examined the correspondence between the informant's CFQ and MFS ratings and participants' performance on the SART and Logical Memory 1. There was a significant negative relationship between participants' performance on the SART and informants' rating on the CFQ $(r=-.49, p<.001)$, indicating that participants who performed better on the SART were perceived by their informant to have fewer problems with attentional 


\section{SELF-AWARENESS AND AGING}

control in daily life. There was a significant positive relationship between participants' performance on Logical Memory 1 and informants' rating on the MFS ( $r$ $=.46, p<.001)$, indicating that participants who performed better on Logical Memory 1 were perceived by their informants to have fewer memory problems in daily life.

Table 3 about here

Figure 2 about here

\section{Is online error awareness related to awareness of daily functioning?}

To test our hypothesis that online error awareness would be related to awareness of daily functioning as measured by the CFQ, MFS and SEQ, partial correlations were conducted controlling for group, speed of cognitive response, speed of motor response, anxiety and depression (see Table 4). Online error awareness was correlated with CFQ-D $(r=-.42, p<.017)$ and MFS-D $(r=-.30, p=.017)$. CFQ-D and MFS-D were also correlated with each other $(r=.34, p<.017)$.

\section{Table 4 about here}

To determine whether the relationships between the different measures of awareness were present within each group independently, partial correlations controlling for speed of cognitive response, speed of motor response, anxiety and depression were conducted for the young and older adults separately for each group (see Table 5). For the young adults online error awareness was significantly correlated with CFQ-D $(r=-.35, p<.017)$. For older adults online awareness was significantly 
related to CFQ-D $(r=-.49, p<.017)$ and MFS-D $(r=.37, p<.017)$. CFQ-D and MFS-D were also correlated with each other $(r=.59, p<.017)$.

Table 5 about here

\section{How does self-awareness relate to other neuropsychological measures?}

To test our hypothesis that self-awareness would be specifically related to sustained attention and memory capacities, partial correlations were conducted between online awareness, CFQ-D, MFS-D, SEQ-D, sustained attention, memory and verbal fluency, while controlling for the effects of group, speed of cognitive response, speed of motor response, anxiety and depression. Online awareness was correlated with sustained attention $(r=.33, p<.008)$. No relationship survived Bonferroni correction when the partial correlation analyses were conducted for each group independently. 


\section{DISCUSSION}

This is the first multi-domain assessment study of self-awareness (SA) in healthy older adults. As predicted, the results revealed significant impairments in SA in older adults, as measured by online error awareness and questionnaire discrepancy scores measures. Older, compared to young, adults were aware of $25 \%$ less of their errors on the Error Awareness Task even though their performance accuracy was matched to that of young adults, and older adults also under-reported attentional lapses and memory failures in daily life relative to observations by a significant other. These deficits could not be attributed to group differences in speed of cognitive response, speed of motor response, anxiety or depression. We also found that online error awareness was significantly correlated with questionnaire discrepancy scores measures, suggesting that awareness of performance on this laboratory measure is representative of awareness on real world tasks. Finally, consistent with our previous data and predictions (e.g. Hoerold et al., 2008; O'Keefe et al., 2007; McAvinue et al. 2005, Shalgi et al 2007; Robertson, 2010), we found online error awareness to be specifically correlated with sustained attention capacity, but not with other measures of cognitive function such as memory and verbal fluency.

This is not the first study to identify a deficit in online error awareness in healthy older adults. Some earlier work had also indicated that aging impacts on the ability to signal performance errors (Rabbitt, 1990). However, in a subsequent study, Rabbitt (2002) demonstrated that as the response signal interval (RSI) duration increased beyond $150 \mathrm{~ms}$, older adults showed correspondingly greater improvements in error signaling, and actually achieved levels of performance that were on par with 


\section{SELF-AWARENESS AND AGING}

young adults when the RSI was increased to $1000 \mathrm{~ms}$. It was argued that the previously observed impairments may have been due to the ubiquitous phenomenon of age-related cognitive slowing as opposed to specific deficits in conscious performance monitoring: older adults may not have had enough time to consciously recognize and signal their errors before the onset of the next stimulus (Rabbitt, 2002). However, the task employed in Rabbitt's studies was a self-paced serial choice reaction time task, which may not have been sufficiently complex to simulate the cognitive demands imposed by many daily life situations. Our current findings indicate that older adults do have significant deficits in online error awareness compared to young adults when assessed using a relatively complex task with multiple requirements, even when error- signaling responses were accepted up to three trials following a commission error, and when controlling for general speed of cognitive response, speed of motor response, anxiety and depression. Furthermore, the real-life validity of laboratory measures can only be verified by establishing that they relate to indices of daily functioning, as demonstrated in this study.

It was important to determine that informants provided objective ratings, as is assumed by the discrepancy score method. Significant within-age-group correlations were observed between informant reports of daily life functioning (attention and memory) and performance on the corresponding neuropsychological tests. These findings indicate that the informant reports were unlikely to have been affected by age-related stereotypes or other biases, and substantiate the validity of the discrepancy scores as indices of SA. Older adults significantly underestimated their difficulties with attentional control and memory functioning relative to informants, whereas young adults overestimated their difficulties relative to informants, albeit only significantly so for memory functioning. This suggests that there are systematic 


\section{SELF-AWARENESS AND AGING}

differences between self- and informant-ratings of cognitive functioning in both age groups. In fact, underestimation of abilities amongst high performers is a relatively well-documented finding, which some authors have attributed to a tendency for high performers to compare their proficient performance with an ideal criterion (Hodges, Regehr, \& Martin, 2001; Kruger \& Dunning, 1999; Kruger \& Meuller, 2002). More importantly, underestimation of cognitive abilities is arguably less serious than overestimation, with the latter being more likely to imperil one's safety.

One previous study that used the MFS with healthy older adults found no evidence of reduced awareness of memory functioning (Clare et al., 2010). However, the older adults in the present study were substantially older than those of Clare et al. (average of 7.15 years older and with a lower age bound of 11 years older), and we observed a positive correlation between age and MFS-D indicating that discrepancies increased with age. Further research is required to explore the time-course of agerelated SA changes across a wider age range.

In contrast to measures of cognitive functioning, there was close agreement between participants and informants' ratings of socio-emotional functioning for both age groups. The relative accuracy of SA for socio-emotional functioning compared to SA for cognitive functioning suggests that the aging process is not associated with global SA deficits. This finding is compatible with several other reports of striking dissociations between the accuracy with which various clinical populations appraise some domains of functioning relative to others (e.g. Hart, Sherer, Whyte et al., 2004).

It is worth considering that much variance in socio-emotional functioning is related to non-cognitive personality traits (e.g. Mavroveli, Petrides, Sangareau, \& Furnham, 2009), which may remain relatively stable during the aging process (Starratt \& Peterson, 1997). It is accordingly plausible that representations that older adults 


\section{SELF-AWARENESS AND AGING}

had of themselves in their younger years with respect to socio-emotional functioning may continue to be accurate into late life, independent of changes in the capacity to self-monitor. In line with this hypothesis, the capacity for online error awareness was not related to SA for socio-emotional functioning, while it was significantly related to SA for both attentional control and memory functioning.

The significant relationships between online error awareness and awareness of cognitive functioning lends credence to the view that online error awareness contributes to general representations of abilities (Jenkinson, Edelstyn, Drakeford, \& Ellis, 2009; Larson \& Perlstein, 2009; Ownsworth \& Fleming, 2005; Robertson, 2010). Accordingly, it may be the case that older adults have failed to notice their lapses and errors as they occurred and as a result are not cognizant of the need to update their self-concept in accordance with the onset of cognitive senescence. This would also explain why older adults' reports of attentional control and memory functioning did not differ from those of young adults.

Consistent with previous findings (e.g. Hoerold et al., 2008; O'Keefe et al., 2007; McAvinue et al. 2005, Shalgi et al 2007), we also found a relationship between sustained attention and online error awareness. These findings corroborate the view that being in an appropriate state of vigilance is an important requisite for recognizing errors as they occur, and in turn for accurate SA (Robertson, 2010). By extension deficits or lapses in sustained attention may be the fundamental phenomenon underlying SA deficits (Robertson, 2010).

As pointed out by a reviewer of this paper, it is possible that levels of online error awareness may have been influenced by individual differences in response strategy when performing the EAT. For instance, older adults may have prioritized the primary task of withholding to No-go trials over the secondary task of signaling 


\section{SELF-AWARENESS AND AGING}

errors of commission. Based on our current data it is not possible to determine whether and to what extent older adults may have adopted a different response strategy. However, we contend that the observed correlation between performance on the EAT and two measures of awareness of cognitive functioning in daily life suggests that reduced levels of online error awareness reflect a cognitive deficit in older adults and not differences in response strategy. Nevertheless, further electrophysiological investigations of the covert neural correlates of performance on the EAT should be carried out to further our understanding of the deficit and clarify whether young and older adults employ different response strategies.

An additional potential driving factor behind age-related changes in SA is the defense mechanism of denial. However, McGlynn and Kaszniak (1991) have argued that if defensive denial was important, one might expect more mildly demented patients, who are beginning to undergo changes to cognitive abilities, to show the greatest SA deficits, yet there is evidence that inaccuracy increases with the severity of dementia (e.g. Agnew \& Morris, 1998). Also, in the present study the discrepancy scores for attentional control and memory functioning were significantly related to online error awareness, which was measured in an objective manner. Collectively, these findings suggest that denial is unlikely to have played a major role in the observed age-related differences in SA.

In conclusion, our data suggest that older adults have significant impairments in SA of cognitive functioning as revealed by converging findings across measures of online error awareness, awareness of attentional control and awareness of memory functioning. This is consistent with age-related structural and functional deterioration of the PFC, and is also consonant with the observations of attenuated electrophysiological correlates of error processing and error awareness (e.g. 
Mathewson et al., 2005). The observed SA deficits are of considerable significance as self-perceptions of abilities are likely more influential in determining many of the choices of independently living older adults, irrespective of objectively determined levels of performance. Older adults with inaccurate SA may be at risk of choosing activities beyond their abilities, and are also likely to lack the impetus to compensate for declining cognitive function, or actively engage in activities that have been shown to reduce the risk of dementia, such as cognitively demanding activities and physical activity (e.g. Wang, Xu, \& Pei, 2012). Investigating the potential to train older adults to become more accurate at appraising their abilities seems like an important pursuit for future research. Indeed there is basis for hypothesizing that addressing selfawareness deficits would confer benefits to other cognitive domains by either eliciting intrinsic motivation for implementing compensatory strategies, or fostering readiness for engaging in, and adhering to, therapeutic interventions. Although our present findings suggest that lapses in attention may be the critical phenomena underlying older adults awareness deficits, further work investigating the specific processing impairments that precipitate unaware errors is recommended. Electrophysiological investigations that incorporate an explicit error signaling response and have the potential to parse out the discrete sensory and cognitive components involved in error processing and error awareness will be an important vehicle for furthering this understanding. 


\section{REFERENCES}

Agnew, S. K., \& Morris, R. G. (1998). The heterogeneity of anosognosia for memory impairment in Alzheimer's disease: A review of the literature and a proposed model. Aging \& Mental Health, 2(1), 7-19.

Amador, X. F., Strauss, D. H., Yale, S. A., \& Gorman, J. M. (1991). Awareness of illness in schizophrenia. Schizophrenia Bulletin, 17(1), 113-132.

Balota, D. A., Dolan, P. O., \& Duchek, J. M. (2000). Memory changes in healthy young and older adults. The Oxford handbook of memory, 395-410.

Band, G.P., \& Kok, A. (2000). Age effects on response monitoring in a mentalrotation task. Biological Psychology, 51, 201-221.

Bramham, J., Morris, R. G., Hornak, J., Bullock, P., \& Polkey, C. E. (2009). Social and emotional functioning following bilateral and unilateral neurosurgical prefrontal cortex lesions. Journal of neuropsychology, 3(1), 125-143.

Broadbent, D. E., Cooper, P. F., FitzGerald, P., \& Parkes, K. R. (1982). The cognitive failures questionnaire (CFQ) and its correlates. British Journal of Clinical Psychology, 21(1), 1-16.

Bruce, P. R., Coyne, A. C., \& Botwinick, J. (1982). Adult age differences in metamemory. Journal of Gerontology, 37(3), 354-357.

Burke, D. M., \& Shafto, M. A. (2004). Aging and language production. Current Directions in Psychological Science, 13(1), 21-24. 
Clare, L., Whitaker, C. J., \& Nelis, S. M. (2010). Appraisal of memory functioning and memory performance in healthy ageing and early-stage Alzheimer's disease. Aging, Neuropsychology, and Cognition, 17(4), 462-491.

Clare, L., Whitaker, C. J., Nelis, S. M., Martyr, A., Markova, I. S., Roth, I., \& Morris, R. G. (2011). Multidimensional Assessment of Awareness in Early-Stage Dementia: A Cluster Analytic Approach. Dementia and geriatric cognitive disorders, 31(5), 317-327.

Clare, L., Wilson, B. A., Carter, G., Roth, I., \& Hodges, J. R. (2002). Assessing awareness in early-stage Alzheimer's disease: Development and piloting of the Memory Awareness Rating Scale. Neuropsychological Rehabilitation, 12(4), $341-362$.

David, A. S. (1992). Illness and insight. British Journal of Hospital Medicine, 48(10), $652-654$.

David, A. S., Bedford, N., Wiffen, B., Gilleen, J., David, A. S., Bedford, N., \& Gilleen, J. (2012). Failures of metacognition and lack of insight in neuropsychiatric disorders. Philosophical Transactions of the Royal Society B: Biological Sciences, 367(1594), 1379-1390.

Endrass, T., Franke, C., \& Kathmann, N. (2005). Error awareness in a saccade countermanding task. Journal of Psychophysiology, 19(4), 275-280.

Falkenstein, M., Hohnsbein, J., Hoormann, J., and Blanke, L. (1990): Effects of errors in choice reaction tasks on the ERP under focused and divided attention. In: C.H.M. Brunia, A.W.K. Gaillard and A. Kok (Eds.): Psychophysiological brain research. Vol. 1, pp. 192-195. Tilburg University Press, Tilburg 
Falkenstein, M., Hohnsbein, J., Hoormann, J., and Blanke, L. (1991): Effects of crossmodal divided attention on late ERP components. II. Error processing in choice reaction tasks. Electroencephalography and Clinical Neurophysiology. $78,447-455$

Falkenstein, M., Hoormann, J., \& Hohnsbein, J. (2001). Changes of error-related ERPs with age. Experimental Brain Research, 138, 258-262.

Fleming, J. M., Strong, J., \& Ashton, R. (1996). Self-awareness of deficits in adults with traumatic brain injury: How best to measure? Brain Injury, 10(1), 1-16.

Folstein, M. F., Folstein, S. E., \& McHugh, P. R. (1975). Mini-Mental State: a practical method for grading the cognitive state of patients for the clinician. Journal of Psychiatric Research, 12, 189-198

Gold, B. T., Powell, D. K., Xuan, L., Jicha, G. A., \& Smith, C. D. (2010). Age-related slowing of task switching is associated with decreased integrity of frontoparietal white matter. Neurobiology of aging, 31(3), 512-523.

Grady, C. (2012). The cognitive neuroscience of ageing. Nature Reviews Neuroscience, 13(7), 491-505.

Graham, D. P., Kunik, M. E., Doody, R., \& Snow, A. L. (2005). Self-reported awareness of performance in dementia. Cognitive Brain Research, 25(1), 144152.

Hart, T., Sherer, M., Whyte, J., Polansky, M., \& Novack, T. A. (2004). Awareness of behavioral, cognitive, and physical deficits in acute traumatic brain injury. Archives of Physical Medicine and Rehabilitation, 85(9), 1450-1456. 
Hart, T., Whyte, J., Kim, J., \& Vaccaro, M. (2005). Executive function and selfawareness of "real-world" behavior and attention deficits following traumatic brain injury. The Journal of Head Trauma Rehabilitation, 20(4), 333-347.

Hedden, T., \& Gabrieli, J. D. (2004). Insights into the ageing mind: a view from cognitive neuroscience. Nature Reviews Neuroscience, 5(2), 87-96.

Hester, R., Foxe, J. J., Molholm, S., Shpaner, M., \& Garavan, H. (2005). Neural mechanisms involved in error processing: a comparison of errors made with and without awareness. Neuroimage, 27(3), 602-608.

Hester, R., Nestor, L., \& Garavan, H. (2009). Impaired error awareness and anterior cingulate cortex hypoactivity in chronic cannabis users. Neuropsychopharmacology, 34(11), 2450-2458.

Hodges, B., Regehr, G., \& Martin, D. (2001). Difficulties in recognizing one's own incompetence: novice physicians who are unskilled and unaware of it. Academic Medicine, 76(10), S87-S89.

Hoerold, D., Dockree, P. M., O’Keeffe, F. M., Bates, H., Pertl, M., \& Robertson, I. H. (2008). Neuropsychology of self-awareness in young adults. Experimental Brain Research, 186(3), 509-515.

Hoerold, D., Pender, N. P., \& Robertson, I. H. (2013). Metacognitive and Online Error Awareness Deficits after Prefrontal Cortex Lesions. Neuropsychologia. 51(3), 385-391.

Holroyd, C. B., \& Coles, M. G. (2002). The neural basis of human error processing: reinforcement learning, dopamine, and the error-related negativity. Psychological review, 109(4), 679-709. 


\section{SELF-AWARENESS AND AGING}

Jenkinson, P. M., Edelstyn, N. M., Drakeford, J. L., \& Ellis, S. J. (2009). Reality monitoring in anosognosia for hemiplegia. Consciousness and Cognition, $18(2), 458-470$.

Kruger, J., \& Dunning, D. (1999). Unskilled and unaware of it: how difficulties in recognizing one's own incompetence lead to inflated self-assessments. Journal of Personality and Social Psychology; Journal of Personality and Social Psychology, 77(6), 1121-1134.

Krueger, J., \& Mueller, R. A. (2002). Unskilled, unaware, or both? The better-thanaverage heuristic and statistical regression predict errors in estimates of own performance. Journal of Personality and Social Psychology, 82(2), 180.

Larson, M. J., \& Perlstein, W. M. (2009). Awareness of deficits and error processing after traumatic brain injury. Neuroreport, 20(16), 1486-1490.

Larson, G. E., Alderton, D. L., Neideffer, M., \& Underhill, E. (1997). Further evidence on dimensionality and correlates of the Cognitive Failures Questionnaire. British Journal of Psychology, 88(1), 29-38.

Leuthold,H., and Sommer,W. (1999). ERP correlates of error processing in spatial SR compatibility tasks. Clinical Neurophysiology. 110, 342-357.

Lezak, M. D. (1993). Newer contributions to the neuropsychological assessment of executive functions. The Journal of Head Trauma Rehabilitation.

Lovelace, E. A., \& Marsh, G. R. (1985). Prediction and evaluation of memory performance by young and old adults. Journal of Gerontology, 40(2), 192-197. 
Malec, J. F., \& Moessner, A. M. (2000). Self-awareness, distress, and postacute rehabilitation outcome. Rehabilitation Psychology, 45(3), 227-241.

Mathalon, D. H., Bennett, A., Askari, N., Gray, E. M., Rosenbloom, M. J., \& Ford, J. M. (2003). Response-monitoring dysfunction in aging and Alzheimer's disease: An event-related potential study. Neurobiology of Aging, 24, 675-685.

Mathewson, K. J., Dywan, J., \& Segalowitz, S. J. (2005). Brain bases of error-related ERPs as influenced by age and task. Biological Psychology, 70, 88-104.

Mavroveli, S., Petrides, K. V., Sangareau, Y., \& Furnham, A. (2009). Exploring the relationships between trait emotional intelligence and objective socioemotional outcomes in childhood. British Journal of Educational Psychology, $79(2), 259-272$.

McAvinue, L. P., Habekost, T., Johnson, K. A., Kyllingsbæk, S., Vangkilde, S., Bundesen, C., \& Robertson, I. H. (2012). Sustained attention, attentional selectivity, and attentional capacity across the lifespan. Attention, Perception, \& Psychophysics, 74(8) 1570-1582.

McAvinue, L., O'Keeffe, F., McMackin, D., \& Robertson, I. H. (2005). Impaired sustained attention and error awareness in traumatic brain injury: Implications for insight. Neuropsychological Rehabilitation, 15(5), 569-587.

McEvoy, J. P., Apperson, L. J., Appelbaum, P. S., \& Ortlip, P. (1989). Insight in schizophrenia: Its relationship to acute psychopathology. Journal of Nervous and Mental Disease. 177, 43-47. 
McGlynn, S. M., \& Kaszniak, A. W. (1991). When metacognition fails: Impaired awareness of deficit in Alzheimer's disease. Journal of Cognitive Neuroscience, 3(2), 183-187.

Manly, T., Robertson, I. H., Galloway, M., \& Hawkins, K. (1999). The absent mind: further investigations of sustained attention to response. Neuropsychologia, $37(6), 661-670$.

Murphy, P. R., Robertson, I. H., Allen, D., Hester, R., \& O'Connell, R. G. (2012). An electrophysiological signal that precisely tracks the emergence of error awareness. Frontiers in Human Neuroscience, 6:65, 1-16.

Nieuwenhuis, S., Ridderinkhof, K. R., Blom, J., Band, G. P., \& Kok, A. (2001). Error-related brain potentials are differentially related to awareness of response errors: Evidence from an antisaccade task. Psychophysiology, 38(5), $752-760$.

O’Connell, R. G., Bellgrove, M. A., Dockree, P. M., Lau, A., Hester, R., Garavan, H., Fitzgerald, M., Foxe, J., \& Robertson, I. H. (2009). The neural correlates of deficient error awareness in attention-deficit hyperactivity disorder (ADHD). Neuropsychologia, 47(4), 1149-1159.

O'Connell, R. G., Dockree, P. M., Bellgrove, M. A., Kelly, S. P., Hester, R., Garavan, H., ... \& Foxe, J. J. (2007). The role of cingulate cortex in the detection of errors with and without awareness: a high-density electrical mapping study. European Journal of Neuroscience, 25(8), 2571-2579.

O'Keeffe, F., Dockree, P., Moloney, P., Carton, S., \& Robertson, I. H. (2007). Awareness of deficits in traumatic brain injury: A multidimensional approach 
SELF-AWARENESS AND AGING

to assessing metacognitive knowledge and online-awareness. Journal of the International Neuropsychological Society, 13(01), 38-49.

Ownsworth, T., \& Fleming, J. (2005). The relative importance of metacognitive skills, emotional status, and executive function in psychosocial adjustment following acquired brain injury. The Journal of head trauma rehabilitation, 20(4), 315324

Prigatano, G. P. (2005). Disturbances of self-awareness and rehabilitation of patients with traumatic brain injury: a 20-year perspective. The Journal of head trauma rehabilitation, 20(1), 19-29.

Prigatano, G. P., \& Altman, I. M. (1990). Impaired awareness of behavioral limitations after traumatic brain injury. Archives of Physical Medicine and Rehabilitation, 71(13), 1058-1064.

Prigatano, G. P., \& Schacter, D. L. (Eds.). (1991). Awareness of deficit after brain injury: Clinical and theoretical issues. Oxford University Press, USA.

Pia, L., Neppi-Modona, M., Ricci, R., \& Berti, A. (2004). The anatomy of anosognosia for hemiplegia: a meta-analysis. Cortex, 40, 367-377.

Rabbitt, P. M. A. (1990). Age, IQ, and awareness of errors. Ergonomics, 33, 12911305.

Rabbitt, P. (2002). Consciousness is slower than you think. The Quarterly Journal of Experimental Psychology, 55A(4), 1081-1092.

Robertson I.H. (2010). Anosognosia and error processing in various clinical disorders. In Prigatano G.P. Study of Anosognosia, Oxford: Oxford University Press, pp $321-331$ 
Robertson, I. H., Manly, T., Andrade, J., Baddeley, B. T., \& Yiend, J. (1997). 'Oops!': Performance correlates of everyday attentional failures in traumatic brain injured and normal subjects. Neuropsychologia, 35, 747-58.

Rosen, H. J., Alcantar, O., Rothlind, J., Sturm, V., Kramer, J. H., Weiner, M., \& Miller, B. L. (2010). Neuroanatomical correlates of cognitive self-appraisal in neurodegenerative disease. Neuroimage, 49(4), 3358-3364.

Salthouse, T. A. (1996). The processing-speed theory of adult age differences in cognition. Psychological Review, 103(3), 403-428.

Seltzer, B., Vasterling, J. J., Yoder, J., \& Thompson, K. A. (1997). Awareness of deficit in Alzheimer's disease: Relation to caregiver burden. The Gerontologist, $37(1), 20-24$.

Shalgi, S., O’Connell, R. G., Deouell, L. Y., \& Robertson, I. H. (2007). Absent minded but accurate: delaying responses increases accuracy but decreases error awareness. Experimental Brain Research, 182(1), 119-124.

Suchy, Y., Kraybill, M. L., \& Franchow, E. (2011). Instrumental activities of daily living among community-dwelling older adults: Discrepancies between selfreport and performance are mediated by cognitive reserve. Journal of Clinical and Experimental Neuropsychology, 33(1), 92-100.

Starkstein, S. E., Vázquez, S., Migliorelli, R., Tesón, A., Sabe, L., \& Leiguarda, R. (1995). A single-photon emission computed tomographic study of anosognosia in Alzheimer's disease. Archives of Neurology, 52(4), 415-420. 
Starratt, C., \& Peterson, L. (1997). Personality and normal aging. In P. D. Nussbaum (Ed)., Hand-book of neuropsychology and aging: Critical issues in neuropsychology (pp. 15-31). New York: Plenum.

Tipper, S. P., \& Baylis, G. C. (1987). Individual differences in selective attention: The relation of priming and interference to cognitive failure. Personality and Individual Differences, 8(5), 667-675.

Van Veen, V. \& Carter, C.S. (2002) The timing of action-monitoring processes in the anterior cingulate cortex. Journal of Cognitive Neuroscience, 14, 593-602.

Wechsler, D. (1997). WAIS-III: Administration and scoring manual. San Antonio, TX: The Psychological Corporation.

Wallace, J. C., Kass, S. J., \& Stanny, C. J. (2002). The cognitive failures questionnaire revisited: Dimensions and correlates. The Journal of general psychology, 129(3), 238-256.

Wallace, J. C., \& Vodanovich, S. J. (2003). Can accidents and industrial mishaps be predicted? Further investigation into the relationship between cognitive failure and reports of accidents. Journal of Business and Psychology, 17(4), 503-514.

Wall, S. E., Williams, W. H., Morris, R. G., \& Bramham, J. (2011). The development of a new measure of social-emotional functioning for young adolescents. Clinical child Psychology and Psychiatry, 16(3), 301-315.

Wang, H. X., Xu, W., \& Pei, J. J. (2011). Leisure activities, cognition and dementia. Biochimica et Biophysica Acta (BBA)-Molecular Basis of Disease, 1822(3), 482-491. 
Young, M. S., \& Bunce, D. (2011). Driving into the sunset: supporting cognitive functioning in older drivers. Journal of aging research, 2011, 33-39.

Zigmond, A. S., \& Snaith, R. P. (1983). The hospital anxiety and depression scale. Acta Psychiatrica Scandinavica, 67(6), 361-370. 


\section{TABLES}

Table 1

Demographic and neuropsychological data for both age groups: mean (SD).

\begin{tabular}{lll}
\hline & $\begin{array}{l}\text { Younger Adults } \\
(\mathrm{n}=45)\end{array}$ & $\begin{array}{l}\text { Older Adults } \\
(\mathrm{n}=45)\end{array}$ \\
\hline Age & $22.70(4.87)$ & $76.16(7.06)$ \\
Age Range & $18-34$ & $66-90$ \\
Sex & 14 Male, 31 Female & 16 Male, 29 Female \\
Years of Education & $14.93(1.16)$ & $15.10(3.61)$ \\
HADS: Anxiety* & $6.34(3.14)$ & $3.61(2.60)$ \\
$\quad$ Depression* & $3.61(1.92)$ & $2.07(2.37)$ \\
NART estimated IQ & $112.42(5.82)$ & $115.04(7.17)$ \\
MMSE* & $29.36(1.00)$ & $28.24(1.17)$ \\
Logical Memory (Delayed recall)*** & $46.10(8.13)$ & $37.49(7.99)$ \\
SART: \% No-go trial accuracy** & $88.73(8.90)$ & $82.09(10.26)$ \\
$\quad$ Go trial response time $(\mathrm{ms}) * * *$ & $257.27(31.03)$ & $352.22(67.49)$ \\
Verbal Fluency (Animal Naming)*** & $30.67(6.95)$ & $22.91(4.72)$ \\
CRT: Cognitive Response (ms)*** & $358.74(51.83)$ & $456.96(81.23)$ \\
$\quad$ Motor Response (ms) $)^{* * *}$ & $549.74(67.36)$ & $729.94(121.40)$ \\
\hline *** $p<.001 ; * * p<01 \cdot * p<.05$ & &
\end{tabular}


Table 2.

Comparison of performance indices on the EAT for younger and older adults: mean (SD)

\begin{tabular}{|c|c|c|}
\hline & $\begin{array}{l}\text { Young Adults } \\
(\mathrm{n}=45)\end{array}$ & $\begin{array}{l}\text { Older Adults } \\
(\mathrm{n}=45)\end{array}$ \\
\hline Mean Stimulus Duration (ms)* & $696.05(157.47)$ & $775.58(138.16)$ \\
\hline Accuracy (\%) & $60.27(12.47)$ & $59.29(10.29)$ \\
\hline Repeat Accuracy (\%) & $72.11(13.99)$ & $66.75(11.68)$ \\
\hline Colour accuracy (\%) & $48.42(14.86)$ & $51.80(13.88)$ \\
\hline Error awareness $(\%)^{* * *}$ & $81.83(15.35)$ & $57.17(21.01)$ \\
\hline Repeat Awareness (\%)** & $79.74(16.79)$ & $53.69(20.22)$ \\
\hline Colour Awareness (\%)** & $86.70(14.55)$ & $61.43(24.46)$ \\
\hline Mean Go-Trial RT (ms) ${ }^{* * *}$ & $423.54(62.11)$ & $563.58(60.80)$ \\
\hline
\end{tabular}

${ }^{* * *} p<.001 ;{ }^{* *} p<.01 ;{ }^{*} p<.05$. 


\section{SELF-AWARENESS AND AGING}

Table 3

Mean (SD) self-ratings, informant-ratings, corrected discrepancy scores, and estimated marginal means of corrected discrepancy scores for the CFQ, the MFS and the SEQ.

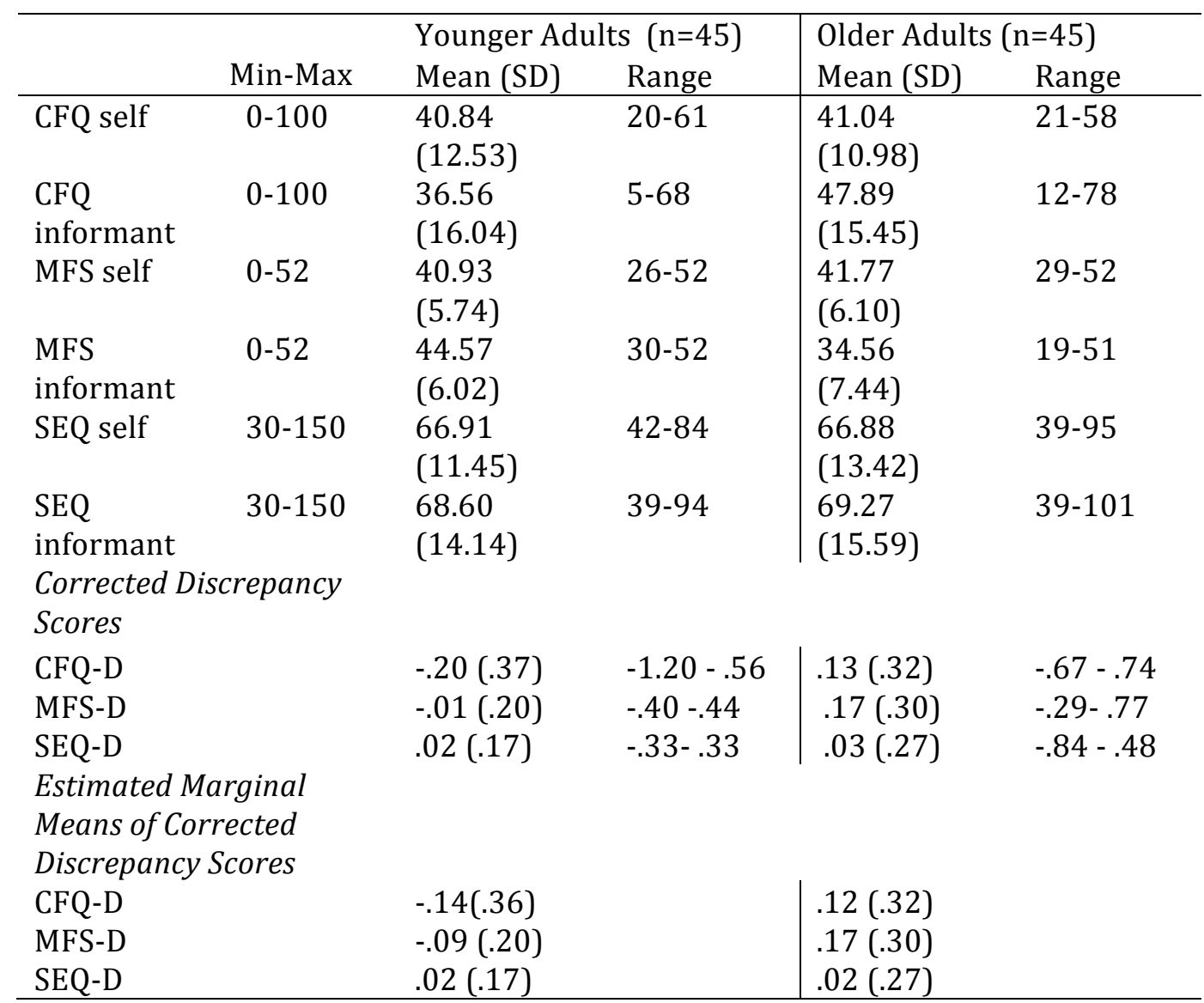




\section{SELF-AWARENESS AND AGING}

Table 4

Partial correlations between error awareness and corrected discrepancy scores with group, speed of cognitive response, speed of motor response, anxiety and depression partialled out.
Measure
1.
2.
3.
4.

1. Online Awareness (EAT)

Partial $r$

2. CFQ-D

Partial $r$

$-.42^{*}$

3. MFS-D

Partial $r$

$-.30 * \quad .34 *$

4. SEQ-D

Partial $r$

$-.17 \quad .20$

.19

$* p<.017$. 


\section{SELF-AWARENESS AND AGING}

Table 5

Partial correlations between online awareness and corrected discrepancy scores with speed of cognitive response, speed of motor response, anxiety and depression partialled out for young adults (A) and for older adults (B)
Measure
1.
2.
3. 4.

1. Online Awareness (EAT)

Partial $r$

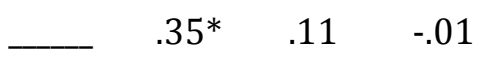

2. CFQ-D

Partial $r$

$-.49 * \quad .10 \quad-.05$

3. MFS_D

Partial $r$

$-.37 * \quad .59^{*}$

.14

4. SEQ_D

Partial $r$

$-.15 \quad .30 \quad .18$

Note. Partial correlations for young adults are presented above the diagonal $(n=45)$, and partial correlations for older adults are presented below the diagonal $(\mathrm{n}=45)$

$* p<.017$ 


\section{FIGURES}
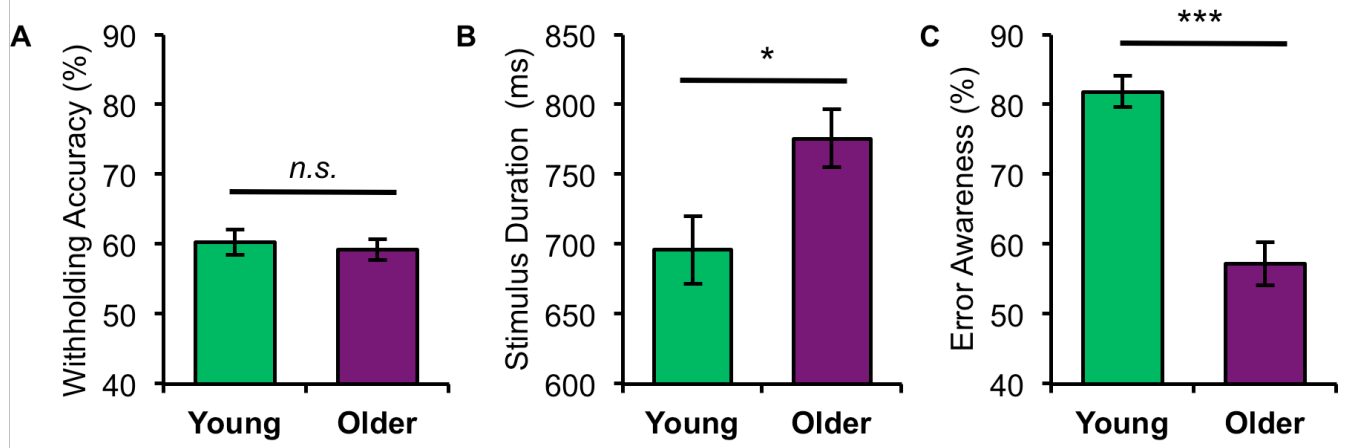

Figure 1. There were no group differences in withholding accuracy (A), but older adults required longer stimulus durations than young participants to attain such levels of accuracy (B). Despite comparable accuracy levels, older adults were aware of a substantially smaller percentage of their errors relative to young adults (C). 


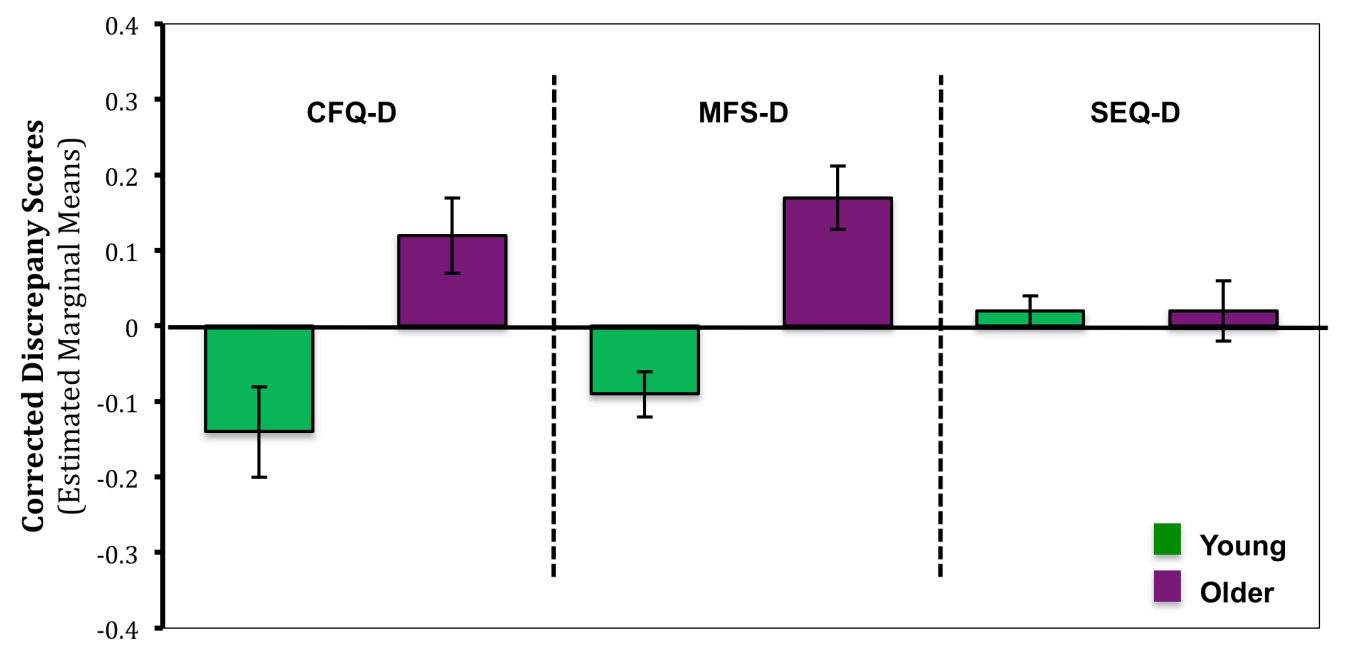

Figure 2. Corrected discrepancy scores (displaying estimated marginal means that take into account the covariates) for young and older adults on the Cognitive Failures Questionnaire, Memory Functioning Scale and Socio-emotional Questionnaire. Young participants reported more difficulties with attentional control relative to informants, whereas, older adults reported fewer difficulties with attentional control relative to informants (CFQ-D). Young adults also reported more difficulties with memory functioning relative to informants, whereas older adults reported fewer difficulties relative to informants (MFS-D). Both groups of participants showed close agreement with their informants for socio-emotional functioning (SEQ-D). 